\title{
Value management in practice: an interview survey
}

Therese Daddow (School of Construction Management and Property, Queensland University of' Technology, Australia) and Martin Skitmore (School of Construction Management and Property, Queensland University of' Technology, Australia)

\section{ABSTRACT}

Despite its obvious theoretical benefits, there have been some reservations regarding the practical implementation of Value Management (VM) for construction projects. In particular, these concern the extra time and costs involved in conducting VM in relation to the actual benefits gained as a consequence of its use. This paper provides the results of an interview survey of the experiences and observations of 17 professionals working in the property and construction industry to establish the extent to which this is an issue. The main conclusion is that the process is working well, with VM being popular among those with experience in its use - which has been extended even into the area of consultant selection. However, in contrast with the prescriptive literature, much of the participants' experiences appear to be more concerned with VM's contribution to the identification and management of the risks involved in project delivery than straight value-for-money aspects. This may be due to the higher levels of uncertainty involved in construction work than VM's original use in manufacturing.

Keywords: Value management, practice, applied, construction, property, survey.

\section{INTRODUCTION}

From its transparent origins in the manufacturing industry 54 years ago, the value analysis tool has evolved through various names and derivative concepts (Adam, 1993) into the well known Value Management (VM) process, which is used to manage key industry drivers such as cost, quality and time'. VM incorporates concepts of design management, life cycle costing (LCC), risk management and human resource management (Daddow, 2002) and is formally aimed at achieving best value for money (both in terms of the decisions arising from the process, the resultant product and the process itself) to ensure best use of time and resources. It is its explicitness, together with VM's applicability to all aspects of industry and business, that is seen to offer its greatest potential to improve business operations and positively influence the end product (Martin, 2001c).

In the construction industry, the use of VM is said to have increased Australia's competitiveness and encouraged growth by facilitating better, justified decisions (Institute of Value Management, 2001) within a "business strategy enrichment system" (Martin, 1997).

For construction project delivery, such enhanced decision making opportunities exist in all project phases: inception, design, construction and disposal (Kinnan and Martin, 2001); allowing VM to be introduced at any stage of a project, with the later stages being used to facilitate project integration and procurement, often through the use of buildability concepts and partnering (Hyuan, 1997). In the absence of VM, significant additional costs can be incurred in late design changes (Dell'Isola, 1982) as well as:

1. Outcomes that represent poor value for money;

2. Inappropriate strategies for providing service needs;

3. Poor definition of service needs;

4. An asset operation that cannot support service delivery;

5. Ineffective communication among client/owners;

6. Deficient project briefs; and

7. Lack of project ownership by end users and managers. (Queensland Department of Public Works and Housing, 1996).

It is therefore not surprising to find that VM in the construction industry has received attention and support from the Australian State and Federal Governments since the early 1990's (Institute of Value Management, 2001) and for many its use is becoming a requirement in the development and assessment of projects. At the time of writing, for the New South Wales NSW Government at least, a VM workshop must be conducted for capital works projects exceeding AUD5 million (NSW, 1990), while in the USA incentive provisions, or a system of rebates referred to as VM incentive clauses - are increasingly being introduced into contracts to formalise the arrangements between the parties for sharing the costs involved in using VM (Thiry, 1997). At this rate of adoption, therefore, it is likely that VM will ultimately become a mandatory requirement in a similar way to Quality Management in the 1980's.

However, in a recent Australian survey (Clark, 2000:9), 43\% of industry respondents stated that contracts are commonly awarded according to the lowest up-front cost, rather than value for money - indicating a surprisingly low VM uptake in view of the potential benefits claimed. One suggestion for this is that

${ }^{1}$ Various terms are used interchangeably with VM (Martin, 1997; Systematic Analytic Methods and Innovations, 2001): including Value Analysis (Dean, 1997; European Commission, 1999); Value Engineering (Mantel \& Meredith, 1995; Ritz 1994; Systematic Analytic Methods and Innovations, 2001); and Value Program (Martin, 2001c), while there are further developments and complimentary systems such as: Earned Value Management (Office of the Under Secretary of Defense, 2001); Group Decision Support (Engineering and Physical Sciences Research Council, 2001); Operational Research (Engineering and Physical Sciences Research Council, 2001); Quality Function Deployment (Dean, 1997); SMART VM (Engineering and Physical Sciences Research Council, 2001; Green 2001; Institute of Value Management, 2001) and Value Chain Management (European Commission, 1999; Thompson, 1995; University of Canberra, 1995) 
the positive effects of VM need to be better 'sold' to the industry

(Martin, 1997). Another is that the current allocation of resources by management, and the selection and training of the VM team, may not necessarily provide all the requirements necessary for successful VM. Particular human barriers that

impact on VM concern change and embracing innovation (Covey, 1989) together with the stigma attached to VM as being mainly a cost cutting exercise and an engineering derived concept (Adam, 1993; Systematic Analytic Methods and Innovations, 2001).

A major concern is the cost of the VM workshop, which has been estimated at approximately $0.3 \%$ to $0.5 \%$ of the project value including briefing, workshop and debriefing. According to Adam (1993) and Dobrow et al, (1978) a reasonable benefit ratio of savings to cost to justify this is $10: 1$. Furthermore, at the McGill University in Canada, where a Value Engineering workshop is carried out as part of the curriculum (involving students, real company representatives and real projects with solutions that are available to the participating company for actual use), the maximum return on investment for the companies up until 1993 was 26:1 (McGill, 2001). Systematic Analytic Methods and Innovations (2001) has also reported returns of $40: 1$ for construction projects. An example from an interviewee stated that on a $\$ 400,000$ project the savings were $\$ 12,500$ as well as the acceleration of the onsite program. The cost of the VM workshop in this case was approximately $\$ 1,000$, resulting in a savings to cost ratio of $12.5: 1$. Whether such a return ratio is obtainable regularly in practice is a moot point. For example, many believe VM to be inappropriate for small projects (CIB, 1997), with projects less than AUD500,000 typically failing to generate the required added value (Kinnan and Martin, 2001).

Another suggestion for the lack of VM take up is the endemic aversion to change in the construction industry. VM encourages and provokes the VM team to think outside the expected - to challenge the status quo and existing boundaries - and deliver alternatives that are intended not to decrease the reliability or compromise the quality of a project (Adam, 1993). The actual outcomes of the changes identified are, however, uncertain as there are often no precedents. This creates resistance as a result of the perceived risks - risk of failure, risk of success and risk of repercussions (Stokes, 1998) - the fear of the unfamiliar and a general reluctance to take the initiative and accept new ideas (Bordass, 2000).

Yet another possibility is the client/owners' lack of support of, and integration into, the VM team (Fowler, 1990) and the clarity of their objectives. Of course, VM can serve as a risk management tool once the client/owner objectives are known. However, it cannot realistically attempt to anticipate actions and problems that occur during a project, or the client/owners' changing requirements for the project in the future (RICS, 2000). departure, therefore, the research starts. In particular, we ask questions relating to the current perceived inadequacies of VM the attitudes and competencies needed of the participants and problems encountered - so that possible improvements may be identified for future development in practice.

\section{SURVEY}

As VM is quite infrequently practiced on construction projects, those experienced in the process form quite a small, specialised group. They are also very busy practitioners, with little time available for participating in focus group work. These circumstances, therefore, clearly dictated the use of interview survey for data collection as this would help provide some opportunities for aggregation of views and subsequent generalisation.

Before designing the interview protocols, preliminary discussions were held with staff members in the Brisbane and Sydney offices of a major international property and construction company. These were originally totally unstructured and simply concerned with the relationship between the theoretical and prescriptive aspects of VM and what actually happens in practice. They sought to identify those issues of most practical importance in the use of VM. These discussions continued to take place informally throughout the duration of the research as an aid to developing the protocols for, and interpreting the data obtained from, the interview survey. Further discussions were also held with staff of the same company in the USA concerning various aspects of VM in their different businesses and environments. This resulted in a set of survey questions oriented around the identified topics.

The interview survey itself was conducted with individuals during 2002 in the interviewee's own office or through conference call facilities. This involved a total of 17 professionals from a variety of organisations, including VM practitioners, project managers, developers, engineers, town planners, interior designers, services consultants and quantity surveyors (Table 1). All were chosen because of their practical experience in working on Value Managed projects. Only one of the interviewees' organisation undertakes regular surveys with client/owners to increase awareness of VM to ascertain its effectiveness. 


\begin{tabular}{|c|l|l|}
\hline No & Title & Company \\
\hline 1 & Associate Director and Branch Manager & Structural Engineers \\
\hline 2 & Professor & University of Canberra, \\
\hline 3 & Facilities Information Coordinator & Bank Client \\
\hline 4 & Associate partner & Services Engineers \\
\hline 5 & Managing Director & Value Managers \\
\hline 6 & Director & Interior Designers \\
\hline 7 & Associate partner & Quantity Surveyors \\
\hline 8 & Associate partner & Town Planners \\
\hline 9 & Senior Consultant & Value Management Centre \\
\hline 10 & Director & Value Management Centre \\
\hline 11 & Design Acceptance Engineer & Military Client \\
\hline 12 & Managing Director & Developer \\
\hline 13 & Preconstruction Services Director & Developer \\
\hline 14 & Knowledge Captain for Manage Design & Developer \\
\hline 15 & Senior Consultant & Developer consultant \\
\hline 16 & Consultant & Developer \\
\hline 17 & Chief Estimator & Developer \\
\hline & & \\
\hline
\end{tabular}

Table 1: Interviewees

Though an outline of the questions was developed for the interviews, the details evolved as the number of interviews progressed. The questions were also adapted for each interview as a result of:

A need to define a question concisely and in a clearer sense to meet the interviewee's knowledge of VM;

The interviewee's discipline;

Further questions deriving from new found information obtained during the interview;
- Adaptation to the extent of the interviewee's experience in a particular aspect of VM; and

- Where the interviewee was unfamiliar with standard VM terminology, providing questions to clarify the VM concepts utilised by interviewee.

Table 2 provides the descriptive words used most frequently during the interviews in association with the perceived practice of VM.
- Basic function

- Worth

- $\quad$ Alternatives

- $\quad$ Life cycle costing

- Value adding

- $\quad$ Short and long term goals

- Problem solving

- Functional space

- Client/owner definition

- Facilitation

- $\quad$ Integrating values (Barton, 2002)

- Creating values
- Cost savings

- Benefit

- Participatory planning

- Best value / best practice

- $\quad$ Value for money management (Barton, 2002)

- Client/owners philosophy

- Project intent

- $\quad$ Space utilisation

- Process

- $\quad$ Structured

- Multi-disciplined teams / collective knowledge

- Rationalisation of optimisation

Table 2: Most frequently descriptive words used in association with the perceived practice of VM. 
For convenience in reporting, the results of the interviews are divided into four major groups. These concern VM usage, the VM team, the extent of use of VM and the use of VM as a risk management tool

\section{Usage}

The interviewees indicated an average $33 \%$ acceptance of the VM workshop and its purpose and impact on projects. This seemingly low average is a result of the influences and disciplines that the interviewees brought to their interviews (i.e., the lowest acceptance was $2 \%$ whilst the highest was $100 \%$ ). One interviewee stating that Australian consultants compare well internationally in the use of VM - being reasonably focused on VM as a result of their general business practices. Another interviewee mentioned that, in order to better manage stakeholders, his organisation finds it useful to identify direct and indirect stakeholders - these being the organisation's staff and customers and the general public respectively.

In addition to achieving better value for the same money, several interviewees commented that VM decisions sometimes resulted in additional initial costs in order to achieve longer-term benefits. For example, it was mentioned that for a project in Houston, USA, the quantity surveyor ascertained that including an additional $\$ 625,000$ in the budget estimate to move a pool deck to another floor would allow a number of additional rooms to be constructed. This had the effect of releasing more usable floor area, which would generate sufficient future income over the life of the project to make the initial $\$ 625,000$ capital outlay seem insignificant.

One interviewee's organisation also uses VM in appointing their design consultants. Instead of taking the lowest consultancy tender, they use a scoring system that takes into account methodology, cost, technical capabilities, expertise and the nominated project team - the consultant closest to the average score being the one that is selected.

\section{The VM team}

Many of the interviewees' comments concern the attributes of the people involved in the VM process. These can be conveniently sub-divided into those associated with the group/ team and those associated with the individuals involved.

\section{Team Attributes}

A frequent assertion in the VM literature is the need for a shared commitment to achieving the project objectives. Interviewees considered the attributes needed for a successful VM workshop to be:

A belief that there is always a better way;

A desire to continuously and constructively challenge normal expectations;

A co-operative approach;

A willingness to break down barriers;

An ability to generate enthusiasm and maintain a positive orientation;

A readiness to seek help and advice, and reciprocate where appropriate:
The existence of common goals;

A good knowledge of the construction industry;

A knowledge of the specific technical area under consideration;

The maintenance of individual self-esteem;

Open and free communication;

Sufficient experience and expertise;

A desire to achieve a quality outcome;

A need to take ownership of the VM workshop outcome;

A combination of professionals from different disciplines;

Sufficient client participation and their knowledge of design, fitout and costings; and

- The presence of a team leader or facilitator to steer the VM workshop.

In respect of the need for open communication, one interviewee pointed out that, although his organisation was highly hierarchically structured, this was diluted during the VM workshop due to the input from external stakeholders and the requirements of the VM team.

Similarly, other interviewees acknowledged that care must be taken to avoid being offensive when giving feedback in the workshop. A particular example was given of an architect dictating a design without taking into account the needs of other stakeholders. As one interviewee stated, this can be compounded when sub-consultants are absent from meetings or just not engaged until later in the process. In general, however, architects do seem to appreciate the feedback provided by the VM team and the value that it will bring to the completed project.

Another interviewee also mentioned the capacity of some service consultants to represent a range of services - fire, electrical, hydraulic and mechanical services for example which has the practical advantage of allowing individual service consultants to attend design meetings on behalf of the services design team, thus maximising the efficiency of their service.

\section{Personal Skill Attributes}

The following ideal skills required of those participating in VM workshops were identified:

Lateral thinking ability and intuition;

An inquiring mind;

Industry expertise;

Life experiences;

A positive, constructive approach;

Knowledge of the client/owner requirements;

Motivated and enthusiastic;

Proactive;

Attentive;

Smart thinking;

Having an open mind and an objective approach to

communication;

Having personal skills;

No preconceived ideas;

Able to bring expertise to the VM workshop;

Ability to communicate ideas confidently and professionally;

Confidence;

Understanding that what people may say, may not be quite 
what they mean, so they need to be able to interpret and 'read between the lines';

Recognise reactions whether verbal or physical;

Able to listen to other ideas and relate to others; and

Be adaptable and flexible.

It was also observed that people involved in successful VM workshops generally have a positive attitude and a desire to contribute to a successful project. They further develop an attitude that seeks to achieve a better project when placed in a focused team. In parallel, client/owners that have been involved with VM tend to value the experience and the resultant effect not only on the project but also within the project team itself.

\section{Extent of use of VM}

For one interviewee, VM is a part of the design synthesis within his organisation's Systems Management - the analysis of customer or user requirements - the synthesis being achieved by developing the design into a workable plan through the use of integrated, multi-disciplinary, product teams. These would generally comprise technicians through to LCC experts, engineers, project managers and management.

The same interviewee said that, in some instances, client/ owners will forgo potential additional benefits because of the extra associated recurring costs involved and their subsequent influence on LCC. In addition, occasional 'all-or-nothing' situations occur, when even partial benefits are not regarded as acceptable, irrespective of their costs.

Another interviewee, on the other hand, noted that the formal use of VM is not undertaken purely on the basis of the project's value, but on the consultant's fee value. In this case, VM workshop attendance could be justified only if this fee was sufficiently large. Though seemingly similar to project value as a criterion for the use of VM (consultant fees being usually proportional to project value), the calculation of the fee together with the level of enthusiasm for VM in general, differs between companies - making the two approaches significantly distinct.

A further interviewee related the case of a client, having witnessed the benefits of a VM workshop, targeting a $15 \%$ savings level for his own project - which was duly achieved!

The interviewees also reflected on the reasons that client/ owners choose to use VM:

1. A commercial company interface where the company has an interest in VM.

2. To maximise the use of available funding in achieving operational requirements.

3. To deliver the best project possible.

4. To obtain a design that supports their corporate culture.

5. Better cohesion within the VM team.

6. Outsourcing responsibilities to privately owned companies.

7. Advances in technology.

8. Change in the end users requirements.

9. Alterations initiated through audits of VM implemented ideas.

10. Mandatory for specific capital works projects.
In contrast, identified reasons for which client/owners choose not to use VM are:

1. They have already experienced VM and it was not a good experience or it did not meet their expectations;

2. Client/owners believe they know exactly what they want in their project;

3. Lack of education on project delivery;

4. Lack of education on VM, its process and benefits;

5. Unwilling to give the time or pay for VM;

6. The client/owners are already paying for the best services of a project manager, quantity surveyor and other project consultants, so there is no need to pay any more for VM; and

7. Perception that VM will not deliver any further benefits, as the same consultants are involved.

\section{VM as a Risk Management tool}

Unlike the use of VM in its original manufacturing context, the greater uncertainties involved in construction have a dominating effect of the VM workshop. These are taken into account in the form of risks as alternative ideas are generated through the VM process and assessed for their value in meeting client/owner expectations. Furthermore, by identifying the project risks, the objectives that are presented for VM are made more realistic. Risk Management (RM) operates in a similar way, although with less emphasis on value maximisation. In the absence of VM or $\mathrm{RM}$, however, project risks are seldom made explicit or considered formally and the project team have little opportunity to manage them effectively. For example, as one interviewee pointed out, if a project is to be constructed upon highly reactive soil that will provide stresses to the end structure, the design consultants would invariably consider it unacceptable to risk minor damages to internal finishes even if structural integrity is maintained. Given the choice, though, the client/owners may well accept this aesthetic risk if $1-2 \%$ of the cost of the foundations could be saved. Similarly, another interviewee observed that long-term owners who want very little maintenance over the next 10-15 years are, if given the option, usually prepared to pay for the up-front costs involved in achieving this.

For all the interviewees, their primary concern underlying VM practice is in the risks involved. Some companies undertake 'trouble shooting' forums where feedback and observations on projects are shared with other colleagues. This not only provides progressive updates to the company on how projects have been successfully designed, but also focuses on the problems that occurred, the risks involved, and how they may be mitigated in future projects.

The interviewees agreed that, in general, it is the management of the three areas of cost, quality and time, and their associated risks, that ultimately determines the success or otherwise of VM and much of what the interviewees considered to be the most salient risks encountered in the practice of VM were provided in these terms. In view of their importance, these results are summarised in some detail in the separate sections that follow. 
Cost

Funding Availability: On high valued projects there can be seemingly abundant funds available. In these cases, therefore, client/owners and other project participants usually do not see the need for VM on the basis that it is perceived as a cost saving tool.

Establishing Project Budgets: Some projects require consultants to provide budget estimates. To ensure that the budgets are reasonable for the intended scope of works initially, the onus is on the consultants to design and specify accordingly. As a result, this can 'fix' the design prematurely, thus boosting the need for later VM. Furthermore, some design consultants place less emphasis on the costing or value aspect of the project.

Initial Designs: The location of key service areas, such as substations and communication rooms, need to be designated early in the design so that unnecessary costs are not incurred as a result of ineffective floor planning. These costs may also include additional expenditure in consultancy fees incurred as a result of revising designs to meet client/owner requirements.

Cost of the Workshop: Obviously, the benefits derived from VM need to exceed the costs of its implementation, but of course there is always a risk that this might not happen. Ironically, these risks are increased by more competent and careful consultants avoiding the more obvious value inefficiencies ahead of the workshop, thereby decreasing the potential benefits that the workshop can identify.

Variation Works: There are instances where design changes are made with no compensatory change to the consultancy fee. To ameliorate this risk to the consultants, however, the cost involved should not only be made trade based, but paid as a project variation across all disciplines.

Client/Owner Expertise: Client/owner lack of expertise and knowledge of the processes required to procure a project is an identified risk. Furthermore, client/owners who do not consult with their consultants or make timely decisions, sometimes find that certain aspects of performance specification sign-offs, project approvals, etc., may not be undertaken adequately. As a result, additional costs and time are expended in following through with the accepted approval processes.

Assessing Cost Effectiveness: For some client/owners, where there have been savings in design through the use of VM, such savings are unable to be quantified accurately and the funds then revert into a 'funding pool' that is used for other projects. Thus, the effectiveness of VM is not quantifiable - increasing the risk of not using VM when it should be used and vice versa.

\section{Quality}

Establishing the Project Brief: If the project brief and objectives have not been detailed clearly and with full agreement between the client/owners, then ambiguity, wrong assumptions or misunderstandings can arise during the procurement of the project. Compounding this, are the different objectives and values attributed to the project by the different stakeholders.
Conversely, it can be uneconomic to provide a detailed project brief for a small valued project because of the fee value relative to the actual service, as well as the time allocated to the procurement of the project by the consultant. Furthermore, the client/owners expectations for the project are usually not directly proportional to the project value and they often expect the same level of service as if it were a higher valued project.

Design Standardisation: On rollout projects where base design requirements are standardised, some client/owners provide a prototype. This prototype is constantly reviewed, assessed and updated from a design and buildability aspect. This may not happen in the absence of a prototype. Within one interviewee's organisation, though VM has been effective, there are cases of innovative ideas, or ideas that have worked well on certain projects, but then being introduced inappropriately into another project.

Impact of Authority Approvals: Depending on the client/owners approach to the project and their experiences, risks relating to authority approval may occur. If the client/owners are aggressive and prepared to challenge legislative requirements, then the design can develop in an innovative manner. If they are not prepared to make this challenge, typically due to the opportunity costs involved in holding the land, they usually stay well within the legislative requirements for quick authority approval. This tends to decrease innovation with design, with some consultants maximising their fee by utilising pre-existing designs they know will be approved without being challenged.

Expert Consultants: When the consultants attend a VM workshop, they may advise the client/owners that their experience with similar projects indicates that undertaking further analysis may not benefit the project. The risk, therefore, is in the costs and time involved in doing the analysis when it is not needed or the loss of quality involved in not doing the analysis when it is needed.

The VM Team: Different words and concepts mean different things to different people and the use of jargon by facilitators needs to be clarified to the VM workshop participants. The VM team may comprise a large number of stakeholders that need to be included during the VM process. By not establishing this relationship, the lack of trust, support and ownership required from the client/owners collectively may make it difficult to meet objectives. Another aspect noted concerns insufficiently experienced graduates placed in decision-making positions.

Identifying Unnecessary Costs: In undertaking VM, identification and analysis of unnecessary costs is not always as obvious as it seems. As a result, a thorough analysis of project components and costs may not be done sufficiently to maximise the effects of VM.

Design Finality: VM workshops are sometimes used as an opportunity to finalise incomplete designs or to rectify mistakes instead of reviewing and bettering the existing design as it is intended. In some cases, additional consultancy fees are incurred for little value in return or more costs are incurred in undertaking the recommended changes. 
Time

Timing of the VM Workshop: Clearly, when VM is not undertaken from early design, the VM potential cannot be fully maximised. Similarly, by undertaking a VM workshop late in a project's development, the project brief may be fixed, limiting the contribution that VM can make.

Expertise of the Facilitator: A VM workshop requires a good facilitator who is experienced in managing the VM process in a way that is suited to the project and the VM team, and in a timely and thorough manner. In addition to establishing a timetable for the VM workshop initially, it is the facilitator's role to manage and maximise the time within each stage of the VM process. If this does not occur, then the VM workshop may not provide the best options, the VM team may not own the outcomes, or the VM workshop may not be adequately completed. Moreover, VM workshops can be affected by the experience of the facilitators and in their preparation leading up to the VM workshop.

Engagement of Consultants: The point of engagement and the type of consultants engaged on the project dictate the extent to which they can usefully undertake VM. Similarly, the financial appraisal of the initial project concept needs to demonstrate that the project is viable before other consultants are engaged. In this respect, the initial input from some engineers can be of limited value until the concept design is completed. Conversely, if the project requires up-front services or structural engineering expertise to establish the concept to which the architectural design and budgets are aligned, then the services and structural consultants may be more involved initially than the architect. In projects where there are sub-consultants, their engagement may not occur until the design is near completion. Generally at this point, the interior finishes and fitout specifications are required in a short timeframe. As a result, some consultants undertake their design services within predetermined and non-negotiable design parameters and with insufficient time available to source the best finishes and or products.

Follow-up Actions: Sometimes, the actions identified by the VM workshop are not implemented. Worse still, some members can act on the anticipated actions of others only to find that no progress has been made when the next VM workshop is undertaken. This not only results in lost program time, but also in increased design costs as a result of reviewing actions from the previous review and frustration generally within the VM team.

Quantity of VM Workshops: The design and construction processes is unnecessarily disrupted and delayed when there are too many VM workshops. Moreover, where designs that have been previously reviewed and updated are used, undertaking VM on each new project wastes time. On the other hand, too few workshops result in lost opportunities for improving the value of design proposals.

Project Development: Too much haste, or the presence of an unskilled facilitator, usually results in a stronger focus on cost savings and time, to the detriment of functionality - creating an imbalance in quality. Similarly, the unstable environment in some industries causes this balance to be distorted. Furthermore, according to one interviewee, for the various outsourcing contractors within their organisation, once a project has been given approval to proceed, the contractors undertake to complete the project as soon as feasible to ensure future work and reputation, but sometimes sacrificing quality in the process.

\section{CONCLUSION}

The survey described in this paper identified the actual experiences and observations of a sample of 17 professionals working in the property and construction industry concerning the VM process and outcomes. In doing so, the main finding was that VM is certainly popular among those with experience in its use.

From the list of words associated with VM, it is apparent that they range from those concerning the basic assumptions underlying the general collective interpretation of 'value management', to those more experienced with the VM process. This range is also reflected in the list of desired attributes of VM team members, which are not only general attributes but also an extension of management skills. This suggests to us that, as VM further advances management philosophy, the attributes needed inevitably become more refined. In addition, in attempting to further understand the extent of VM practice, the survey established that the main reason for its cooperative support by consultants was to gain and further their competitive advantage in delivering projects to the client/owner.

Conversely, it would appear that the main reason for it not being used is due to client/owners' inadequate knowledge of its potential and application.

A large part of this paper concerns the interviewees' experiences of the risks associated with VM. This is in quite distinct contrast to the original use of VM in the manufacturing industry. Situations are identified which in themselves may be used positively within VM by firstly identifying these risks and then how they may be managed. Of course, this would not remove all risks but help in mitigating those remaining, but would also serve as 'lessons learned' for future projects.

\section{REFERENCES}

Adam, E 1993, 'Value Management: cost reduction strategies for the 1990s', Longman Cheshire Pty Limited, Melbourne, Australia.

Barton, Roy 2002, 'Value Management and Complexity in Infrastructure Project Initiation', PhD Thesis, James Cook University, Australia.

Bordass, W 2000, 'Cost and value: fact and fiction', Building Research and Information, 28 (5/6) 338-52.

Clark, L 2000, 'The Need for a new VM Standard in Australia', Paper presented to the Institute of Value Management Australia Conference, Queensland, Australia.

Covey, S R 1989, The 7 habits of highly effective people, Simon \& Schuster, New York, USA. 
Daddow, Therese 2002, 'A Practical Observation of Value Management', Masters Thesis, Queensland University of Technology, Australia.

Dean, E B 1997, Value Engineering from the perspective of competitive advantage ${ }_{\perp}<$ http://mijuno.larc.nasa.gov/dfcl

ve.html>

Dell'Isola, A J 1982, Value Engineering in the construction industry, $3^{\text {rd }} \mathrm{Ed}$. Van Nostrand Reinhold Company Inc., New York, USA.

Dobrow, P V, Macedo, Manuel C and O'Rourke, Joseph J 1978, Value Management for construction ${ }_{\perp}$ John Wiley \& Sons Inc, Toronto, Canada.

Engineering and Physical Sciences Research Council 2001, Group Decision Support for Value Management - http:// www.rdg.ac.uk/ kcsgrest/value management/research.htm

European Commission, 1999, Innovation management building competitive skills in SMEs, European Communities, Belgium.

Fowler, T. C. (1990). Value analysis in design, Van Nostrand Reinhold, New York NY.

Green, S D 2001, Beyond Value Engineering: smart value management for building projects, <http://www.valueanalysis.com/results.htm>

Hyuan, C T 1997, 'Making Value Engineering as an effective tool for project integration using constructability and partnering concepts', Paper presented to the SAVE International Proceedings - 1997 Annual Conference, ed. O James Vogl, Illinois, USA.

Institute of Value Management 2001, Competitiveness through value $_{1}<$ http://www.ivm.ork.uk/aboutivm sig svm 12001.htm>

Kinnan, M., Kinnan, M., Martin, S., 2001, But we already do it, and other misunderstandings $s_{1}<$ http://www.value-analysis.com/ doitpapr.htm>

Mantel Jr, SJ and Meredith, JR 1995, Project Management - a managerial approach, John Wiley \& Sons Inc., Canada.

Martin, S 2001c, Application of value method procedures in non-engineering processes, <http://www.value-analysis.com/ vevspro6.htm>

Martin, S 2001d, But we already do it! <http://www.valueanalysis.com/doalredy.htm>

Martin, S J 1997, 'What's the difference?' Paper presented to the SAVE International Proceedings - 1997 Annual Conference, ed. O James Vogl, Illinois, USA. <http://www.valueanalysis.com/whatdif.htm>

Martin, S J 2001a, Constructively measuring value programs effectiveness, $<$ http://www.value-analysis.com/ measurepaper.htm>

Martin, S J 2001b, Value program and study teams success through cooperative interplay ${ }_{2}<$ http://www.value-analysis.com/ cooppapr.htm>
McGill University (McGill) 2001, Value Engineering at McGill University $_{1}<$ http://www.engineering.mcgill.ca/meproj3.htm>

New South Wales Government 1990, Value Management manual, NSW Government, NSW, Australia.

Office of the Under Secretary of Defense 2001, Earned Value Management $_{1}<$ http://www.acq.osd.mil/pm/faqs/faq.htm>

Queensland Department of Public Works and Housing 1996, Strategic Asset Management - Value Management 7.2, Queensland Government, Australia.

Ritz, G J 1994, Total Construction project Management, McGraw-Hill Inc, USA.

Save International (SAVE) 2001, Benefits of using the value methodology ${ }_{1}<$ http://www.value-eng.org/vmbenefits.htm>

Stokes, E 1998, Unit 303 - Project management, APESMA, Deakin University, Victoria, Australia.

Systematic Analytic Methods and Innovations 2001, Value analysis results, <http://www.value-analysis.com/samifron.htm>

The Royal Institution of Chartered Surveyors (RICS) 2000, Quantity Surveying 2000 - The future role of the Chartered Quantity Surveyor, Godfrey Lang Limited, London.

Thiry, M ed. 1997, The Bovis Self Development Program Executive Module: Value Management, A draft SDP document.

Thompson, J L 1995, 'Strategic management: awareness and change', Journal - Operational Research Society, $2^{\text {nd }}$ Edition, vol. 46 no. 11, pp. 1398.

University of Canberra 1995, Competency Standards for the Value Management Facilitator, UC, NSW, Australia. 